Paper VII

\title{
Modeling and verification of creep strain and exhaustion in a welded steam mixer
}

In: Journal of Pressure Vessel Technology. Vol. 131 (2009), 061405 (5 pages).

Reprinted with permission from the publisher. 

PVT -08-1091

\title{
MODELING AND VERIFICATION OF CREEP STRAIN AND EXHAUSTION IN A WELDED STEAM MIXER
}

\author{
Stefan Holmström (stefan.holmstrom@vtt.fi), Juhani Rantala, Anssi Laukkanen, Kari Kolari, Heikki \\ Keinänen \\ VTT Technical Research Centre of Finland, P.O. Box 1000, FI-02044 VTT
}

Olli Lehtinen, Fortum Power \& Heat, Finland

\begin{abstract}
Structures operating in the creep regime will consume their creep life at a greater rate in locations where the stress state is aggravated by triaxiality constraints. Many structures, such as the welded steam mixer studied here, also have multiple material zones differing in microstructure and material properties. The 3-dimensional structure as such in addition to interacting material zones is a great challenge for finite element analysis (FEA), even to accurately pinpoint the critical locations where damage will be found. The studied steam mixer, made of 10CrMo 9-10 steel (P22), has after 100000 hours of service developed severe creep damage in the several saddle point positions adjacent to nozzle welds. FE-simulation of long term behaviour of this structure has been performed taking developing triaxiality constraints, material zones and primary to tertiary creep regimes into account. The creep strain rate formulation is based on the logistic creep strain prediction (LCSP) model implemented to ABAQUS, including primary, secondary and tertiary creep. The results are presented using a filtering technique utilising the formulation of rigid plastic deformation for describing and quantifying the developing “creep exhaustion".
\end{abstract}

\section{INTRODUCTION}

The structural integrity of high temperature welded structures has been widely studied and published, often however as rather simple girth weld cases [1]-[10]. In these the development of stress (von Mises or maximum principal stress) and strains (axial or hoop) are followed and conclusions regarding critical locations are usually drawn from the locations of maximum stresses or strains. Furthermore simulations are often based on steady state creep strain rates and the impact of triaxiality constraints and multiaxial creep ductility are seldom taken into account. As a consequence these studies often fail to pinpoint the locations where service exposed components actually would develop creep damage. In the design stage this could become a problem emerging later in the life of the component, as it did with the mixer studied here at about half the desired (design) life. The influence of creep ductility exhaustion under multiaxial conditions has 
been studied [11]-[14] and also implemented in design codes [15]-[17] in recent years but the implementation for life management and remaining life predictions of service exposed components is not yet satisfactorily solved. Here the LCSP method [18][19] has been implemented to ABAQUS finite element analysis software and used for the long term creep deformation simulation of a mixer tank with a welded nozzle. The model is able to predict creep in primary to tertiary stage. In addition the evolving creep exhaustion related to multiaxial constraint is visualised through a new filtering technique [20], based on a classical relation [21] for creep ductility ratio. The filtering technique is accurately pinpointing the critical locations (showing most creep damage) in the saddle point of the component. The mixing vessel operates at nominal pressure of 185 bar equalling a skeletal von Mises stress around $37 \mathrm{MPa}$ in the main body when calculated as a simple pipe. The future challenge will be to predict the impact of weld repair for the life extension of the component. The creep models and rupture properties for the material 10CrMo 9-10 are based on the standard EN 10216 [22] and ECCC recommendations [23].

\section{THE ASSESSED STEAM MIXER}

The studied steam mixer (10CrMo 9-10) has after 100000 h severe creep damage (see Fig. 1 and Fig. 2) in the saddle point position adjacent to the weld. The maximum crack lengths encountered were over $200 \mathrm{~mm}$ in length and even with $4 \mathrm{~mm}$ ground from the wall thickness oriented cavitation was still found.

The main dimensions of the steam mixer are:

main body: $\quad$ outer diam. $376 \mathrm{~mm}$, wall $66 \mathrm{~mm}$

nozzle pipe: $\quad$ outer diam. $300 \mathrm{~mm}$, wall $61 \mathrm{~mm}$

The operating pressure of 185 bars introduces skeletal stresses (calculated as pipes) of $31 \mathrm{MPa}$ in the nozzle pipe and 37 $\mathrm{MPa}$ in the main body. The design pressure, selected for the simulation, is 206 bar equalling in 34 and $41 \mathrm{MPa}$ skeletal stresses correspondingly.

At $600^{\circ} \mathrm{C}$ the design stress relates to uniaxial rupture times at about $60000 \mathrm{~h}$ [22], but at the operating temperature of $525^{\circ} \mathrm{C}$ the predicted rupture time exceeds one million hours for parent material which is far beyond recommended extrapolation range. 


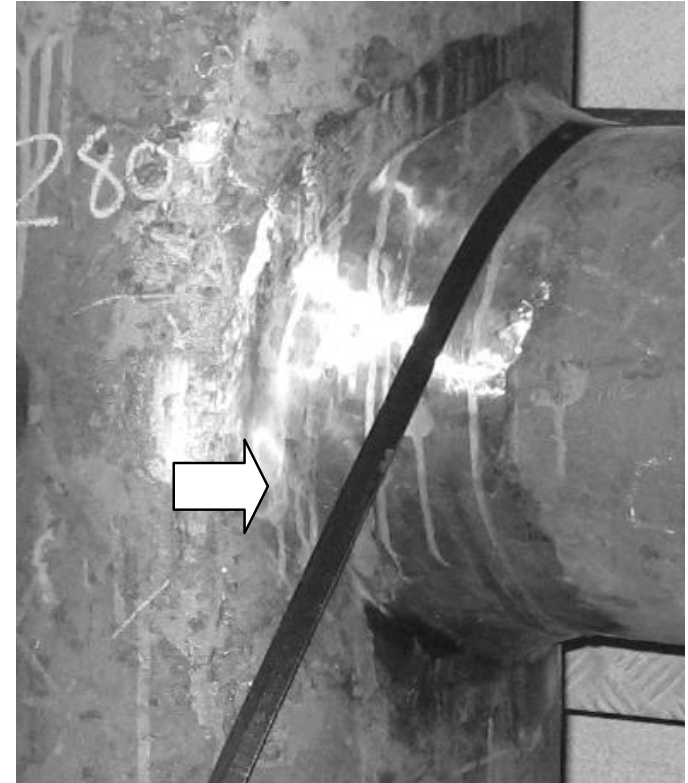

A

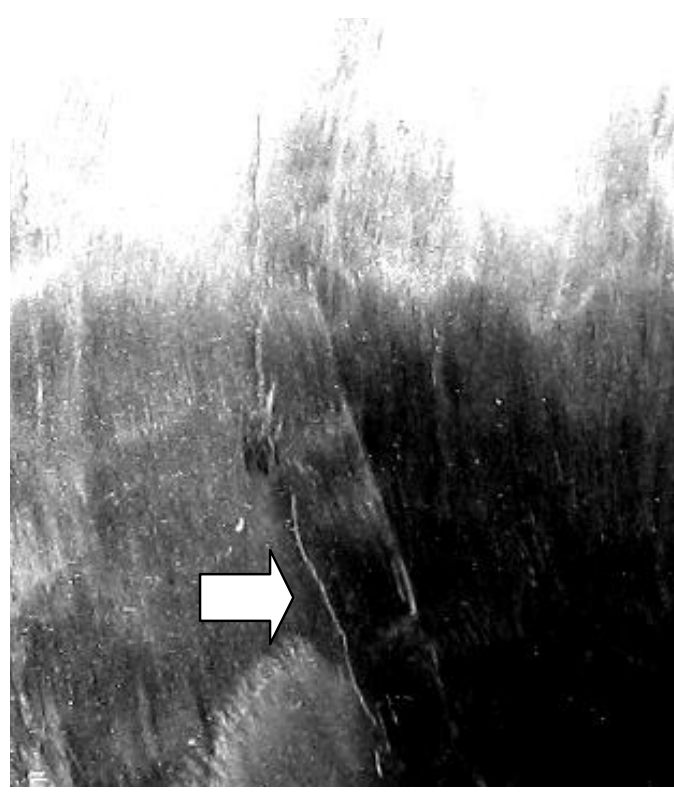

B

Fig. 1. A) Upper nozzle of high pressure mixer. B) Detail of $200 \mathrm{~mm}$ crack at nozzle weld (HAZ).

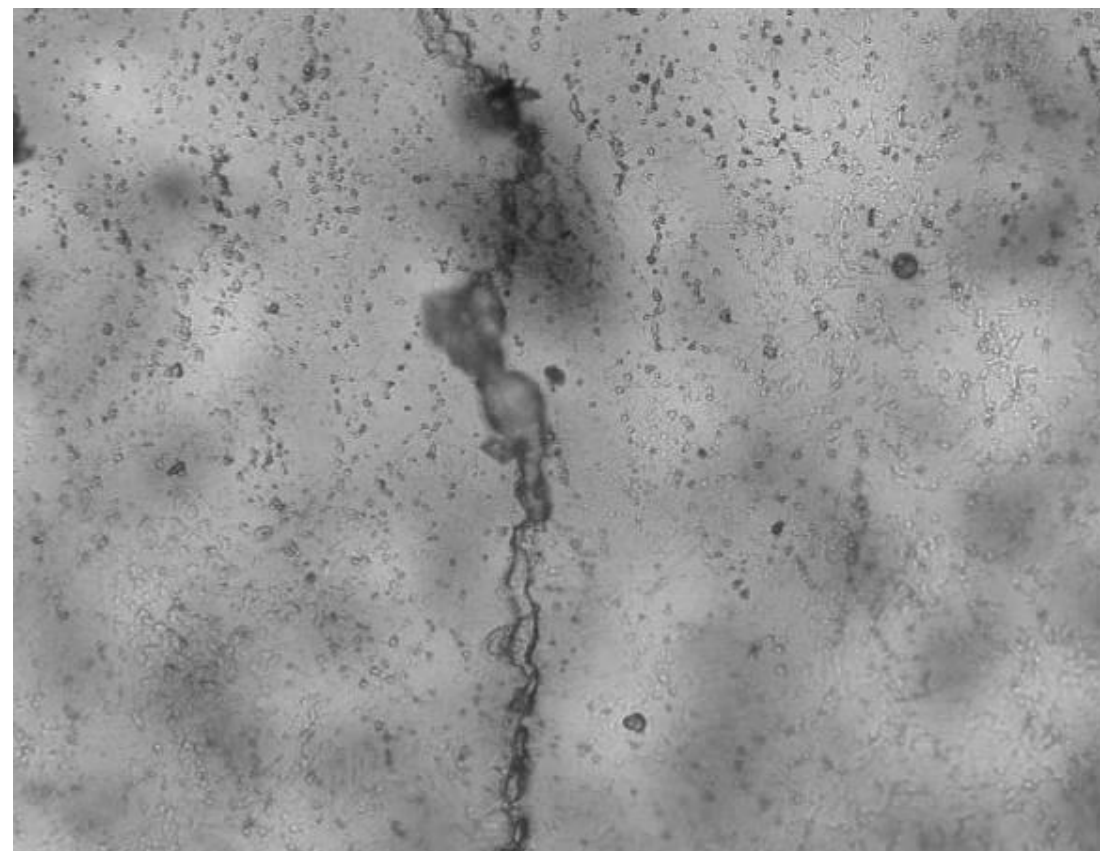

Fig. 2. A) Creep cavitation and crack formation in one of the upper nozzles.

\section{THE STRAIN MODEL}

The creep strain model, logistic creep strain prediction method or LCSP, is based on time to rupture and shape functions. This is also the models greatest strength since nearly the same interpolation and extrapolation robustness can be achieved for the strain model as for the rupture model. The LCSP model assumes that the full creep strain curves at 
specified temperature and stress can be acquired from knowing only the time to rupture and two material specific shape functions $\mathrm{p}(\sigma, \mathrm{T})$ and $\mathrm{x} 0(\sigma, \mathrm{T})$ (see Eq.1).

In LCSP time $t_{\varepsilon}$ to creep strain $\varepsilon^{\text {cr }}$ is defined as

$$
\log \left(t_{\varepsilon}\right)=\frac{\left(\log \left(t_{r}\right)+C\right)}{1+\left(\frac{\log \left(\varepsilon^{c r}\right)}{x_{0}}\right)^{p}}-C
$$

where $t_{\mathrm{r}}$ is the time to rupture from a creep rupture model, and $\mathrm{x} 0, \mathrm{p}$ and $\mathrm{C}$ are fitting factors defining the curve shape. The LCSP can easily be rewritten to give strain at specified time and then differentiated (analytically) to give strain rate as a function of time, stress and temperature.

As an example of the LCSP data fit some short term P22 creep curve data $(0.1,0.2,0.5,1,2,5,10,15 \%$ and fracture strain [18]) of an ECCC short term data set (10CrMo 9-10), is presented in Fig. 3 as accumulated strain against the temperature compensated time to strain (Larson-Miller parameter form).

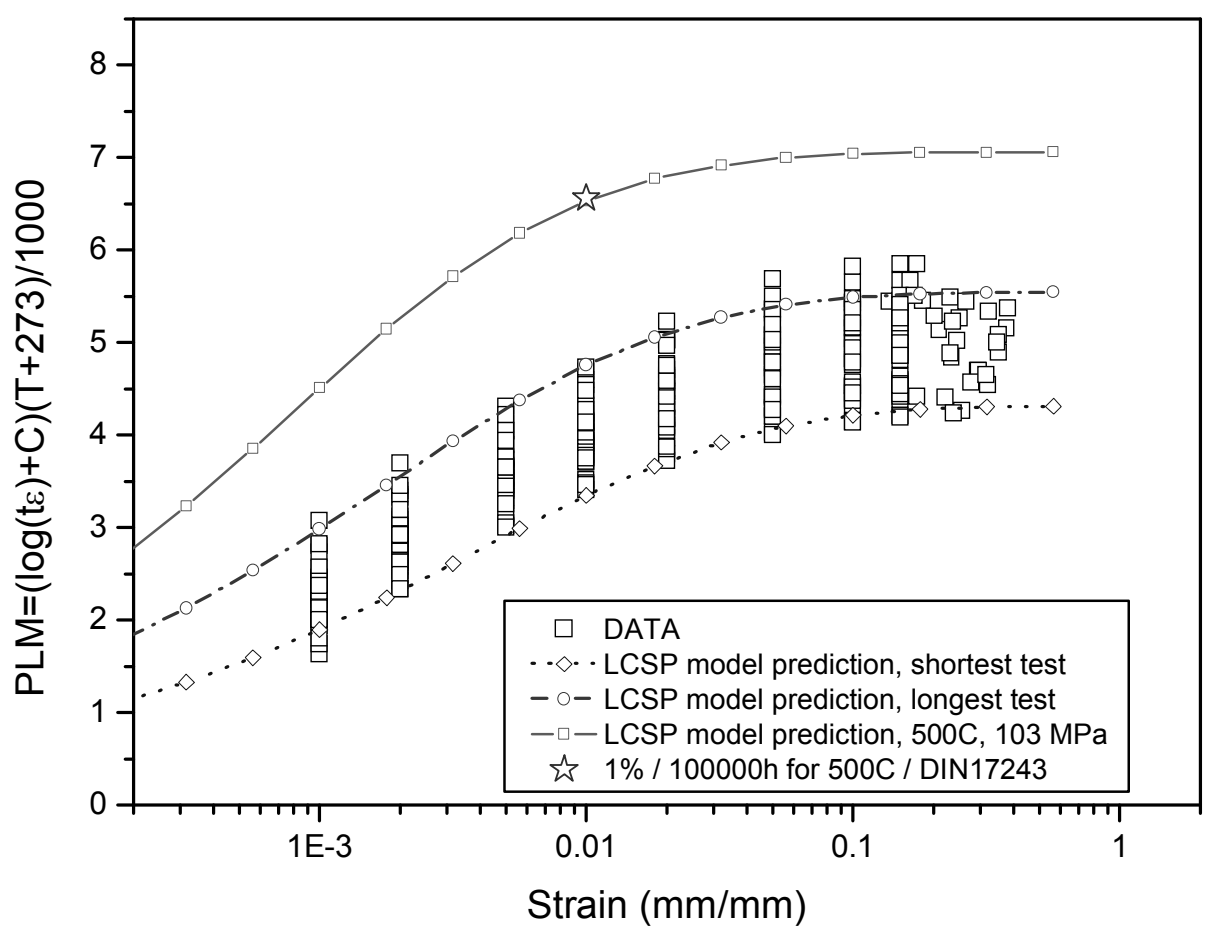

Fig. 3. ECCC short term 10CrMo 9-10 strain data (0.1 to fracture strain) presented in time temperature parameter form with modelled LCSP predictions of longest and shortest test and for the standard value stress $500^{\circ} \mathrm{C} / 103 \mathrm{MPa}$ giving 1\%at $100000 \mathrm{~h}$ (marked as a star, [25]). 
The LCSP model has earlier been successfully implemented on strain measurement data from the same power plant on another steam mixer exceeding $200000 \mathrm{~h}$ of service [26].

For the ABAQUS FEA software the LCSP model has been implemented as a CREEP user subroutine [27]. The subroutine is called at each integration point of the mesh. The steam mixer was modelled using 20-node brick elements (C3D20R). The number of elements in the model was 11592 and the total number of variables (including Lagrange multiplier variables) was 158523.

In the subroutine the equivalent creep strain increment $\Delta \varepsilon^{c r}$ must be defined for each time step. The equivalent creep strain $\varepsilon^{c r}$ must be a conjugate to the von Mises stress $q$ so that the strain energy rate density $\dot{W}^{c r}$ equals

$$
\dot{W}^{c r}=\int_{0}^{\dot{\bar{\varepsilon}}^{c r}} q \mathrm{~d} \dot{\varepsilon}^{c r}=\int_{0}^{\dot{\varepsilon}} \sigma_{\mathrm{ij}}: \mathrm{d} \varepsilon_{\mathrm{ij}}^{c r}
$$

where elastic strain rates are ignored. In the CREEP subroutine the equivalent creep strain increment $\Delta \varepsilon^{c r}$ is then integrated by the Euler backward algorithm:

$$
\Delta \varepsilon^{c r}=\dot{\varepsilon}^{c r} \Delta t
$$

where $\dot{\varepsilon}^{c r}$ is obtained from Eq. (1) after some manipulation.

In addition the following derivate

$$
\Delta K=\frac{\partial \Delta \varepsilon^{c r}}{\partial q}
$$

is required for implicit creep integration.

At very small stresses linearization and Taylor series development has been made both for the rupture master curves (danger of turn-back) and shape parameters (outside range of data), these modifications enable safe operation of the model, i.e. non-physical (such as infinite strain rate) constitutive response does not result from values typically outside the scope of the experimentally determined LCSP model parameters (such as very small field variables and solution time). Terms required by Abaqus, Eqs. 3. and 4., can be computed with relative ease since the LCSP model provides a closed form expression of the equivalent creep strain and creep strain rate. The internal routines of Abaqus translate the uniaxial response to a multiaxial one by using a conventional $\mathrm{J}_{2}$ incremental plasticity flow rule. 


\section{THE CREEP PROPERTIES FOR BM, HAZ AND WM}

The successful simulation of the welded structure needs rupture and shape models for base (BM), weld metal (WM) and heat affected zone (HAZ). In this work, for the heat affected zone (HAZ), it is assumed that the time to rupture is following a $20 \%$ reduction in strength (WSF $=0.8$ ) in relation to the base material. For the WM three different situations were simulated based on different time factors (or normalised rupture time of 1,2 and 0.5) as defined in Eq 9. in relation to the base material as in Table 1 . The base material creep response was defined using a creep rupture master curve (any model type is possible) for P22 material such as the minimum commitment or the Mendelson-RobertsManson (MRM) methods [24] fitted to available rupture data. The rupture master curve can then be applied for $t_{r}$ in Eq 1. together with the creep curve shape functions (Eq. 5-6);

$$
\begin{gathered}
x_{0}(\sigma, T)=-0.391+0.696 \cdot \log (\sigma)-3392.5 /(T+273) \\
p(\sigma, T)=4.363-2.271 \cdot \log (\sigma)+3874.9 /(T+273)
\end{gathered}
$$

in the place of $x 0$ and $p$ in Eq.1.

Material property ratios have been used by Perrin and Hayhurst [2][3] for characterising the creep properties of weld metal and the heat affected zone in relation to the base material. In this work the normalised parameters chosen for characterisation of the material zones are;

$$
\begin{array}{cc}
\text { normalised primary creep strain } & \kappa=\left[\frac{\varepsilon_{\text {prim }}}{\varepsilon_{f}}\right] \\
\text { ratio of minimum creep rates } \beta & \beta=\left[\frac{\dot{\varepsilon}_{\text {min }}}{\dot{\varepsilon}_{\text {min }}^{b}}\right] \\
\text { normalised rupture time } & \xi=\left[\frac{t_{R}}{t_{R}^{b}}\right]
\end{array}
$$

where $\varepsilon_{\text {prim }}$ is the primary creep strain component, $\varepsilon_{\mathrm{f}}$ is the fracture strain (simulated at $95 \%$ of life), $t_{R}$ is the time to rupture and $\dot{\varepsilon}_{\min }$ the minimum creep strain rate. The superscript $b$ (in $\beta$ and $\xi$ ) is indicating the base material property. The resulting normalised property ratios are listed in Table 1 showing the material zone differences. 
Table 1. Calculated and pre-determined material property ratios for BM, HAZ and WM at $525^{\circ} \mathrm{C}$. Note the assumed time factors for the simulated WM (in bold).

\begin{tabular}{|c|c|c|c|}
\hline \multirow{2}{*}{ Zone } & \multicolumn{3}{|c|}{ LCSP simulation } \\
\cline { 2 - 4 } & $\kappa$ & $\beta$ & $\xi$ \\
\hline BM & 0.036 & 1.00 & 0.46 \\
\hline HAZ & 0.035 & 2.58 & $\mathbf{1 . 0 0}$ \\
\hline WM1 (=BM) & 0.036 & 1.00 & $\mathbf{2 . 0 0}$ \\
\hline WM2 & 0.036 & 0.536 & $\mathbf{0 . 5 0}$ \\
\hline
\end{tabular}

An example of predicted creep strain response (uniaxial) in the different zones of a weld at $525^{\circ} \mathrm{C} / 37 \mathrm{MPa}$ is shown in Fig. 4.

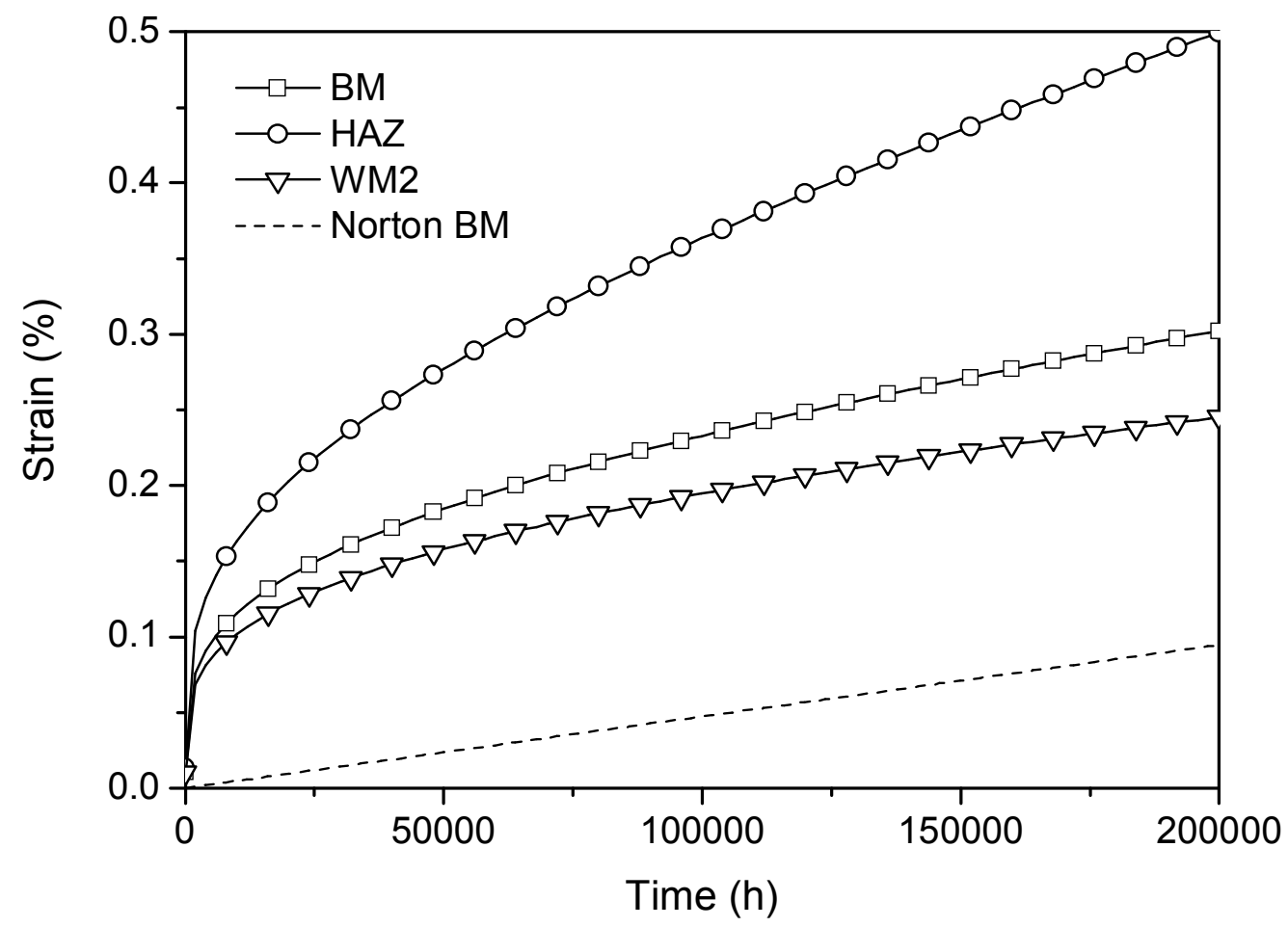

Fig. 4. Simulated creep curves at service pressure and temperature (first 200000 h) for BM, HAZ (WSF=0.8) and WM2 as in Table 1. The dashed line represents the accumulated strain if using minimum creep rate only (BM). 


\section{MANAGING CONSTRAINT BY $\Lambda$-FILTERING}

It is commonly known that for long term creep of pressure vessels the maximum equivalent stresses and strains develop on the inner surface vessel whereas the maximum principal stress will redistribute towards the outer surface due to creep. The multiaxial creep ductility again (due to the triaxiality constraint) will reduce towards the outer surface as creep proceeds under long term service. Therefore a technique for filtering the acquired FE results has been developed using the expression for rigid plastic deformation [11] as presented in Eq. 10-11;

$$
\begin{aligned}
& \Lambda=\frac{\varepsilon^{c r}}{1.65 \cdot \exp (-1.5 \cdot h)}=\frac{\varepsilon_{f u}}{\varepsilon_{f m}} \cdot \varepsilon^{c r} \\
& h=\left[\frac{\sigma_{k k}}{3 \cdot q}\right]
\end{aligned}
$$

Where $\sigma_{k k}$ is the trace of a stress tensor $\sigma_{i j}$, q the von Mises stress, $\varepsilon_{\mathrm{fu}}$ the uniaxial creep ductility, $\varepsilon_{\mathrm{fm}}$ the corresponding multiaxial creep ductility and $\varepsilon_{\mathrm{m}}$ the multiaxial creep strain at the time of observation (momentary strain). Eqs. 10. and 11. are founded on a classical Rice-Tracey type of damage model incorporating the effects of multiaxial stress state to failure strain [29]. The Rice-Tracey approach is the simplest model for inclusion of constraint effects to failure properties, and is founded on an analysis of growth of a spherical void under differing conditions of stress triaxiality. Different stress states yield different void growth rates, thus resulting in the dependency of failure strain on stress triaxiality. The Rice-Tracey approach is particularly feasible due to its simplicity. i.e. it does not couple to the time history of the problem and can be used a filtering technique on top of analysis results.

The filtering technique does not require local creep ductility values since it is expressed as a ratio dependent on stress and momentary strain only. Previous experience from $\Lambda$-filtering has been acquired from finding critical damage locations in simple girth welds [28].

\section{FEA RESULTS FOR THE MIXER}

The mixer case was evaluated under design pressure for the three combinations of weld metals with constant HAZ and BM properties at $600^{\circ} \mathrm{C}$ and for weld metal (WM2) at $525^{\circ} \mathrm{C}$. The $600^{\circ} \mathrm{C}$ simulations were initial test runs with less extrapolation involved (in stress) though at too high a temperature for the material as such. The $525^{\circ} \mathrm{C}$ simulation case represents an actual life prediction at design pressure, however with an extrapolated uniaxial rupture prediction exceeding one million hours. 
The results were studied at 1000 hours for the $600^{\circ} \mathrm{C}$ simulations and at $100000 \mathrm{~h}$ for the $525^{\circ} \mathrm{C}$ simulation. The runtime of the steam mixer simulation to $100000 \mathrm{~h}$ was 8 hours of CPU time ( $8 \mathrm{~h} 20$ minutes of wall clock time) with an $3.80 \mathrm{GHz}$ Intel Xeon PC.

The selected time of study for the $600^{\circ} \mathrm{C}$ cases was determined through a simple Larson-Miller time-temperature transformation. At the selected simulation time strains, stresses and "creep exhaustion" ( $\Lambda$-values as defined by Eq. 10.) were determined (see Table 2).

Table 2. Creep exhaustion localisation (critical location), maximum calculated 1 -value, von Mises stress and maximum principal strain at the specified location.

\begin{tabular}{|c|c|c|c|c|}
\hline Case & Critical location & maximum $\Lambda$-value & $\sigma_{V M}(\mathrm{MPa})$ & $\begin{array}{c}\varepsilon_{1} \\
(\%)\end{array}$ \\
\hline $\begin{array}{l}600^{\circ} \mathrm{C} \\
\text { WM1 }\end{array}$ & $\begin{array}{c}\text { saddle point surface } \\
\text { (HAZ) }\end{array}$ & 0.015 & 54 & 0.5 \\
\hline $\begin{array}{l}600^{\circ} \mathrm{C} \\
\mathrm{WM} 2\end{array}$ & $\begin{array}{c}\text { saddle point surface } \\
\text { (HAZ) }\end{array}$ & 0.018 & 56 & 0.7 \\
\hline $\begin{array}{l}600^{\circ} \mathrm{C} \\
\mathrm{WM} 3\end{array}$ & $\begin{array}{c}\text { overflow at } 422 \mathrm{~h} \\
\text { shear in WM }\end{array}$ & - & - & $>20$ \\
\hline $\begin{array}{l}525^{\circ} \mathrm{C} \\
\mathrm{WM} 2\end{array}$ & $\begin{array}{c}\text { saddle point surface } \\
\text { (HAZ) }\end{array}$ & 0.015 & 57 & 0.6 \\
\hline
\end{tabular}

The $525^{\circ} \mathrm{C}$ simulation results ( $\Lambda$-values, maximum principal strain and von Mises stress) are presented in Fig. 5-Fig. 7. 


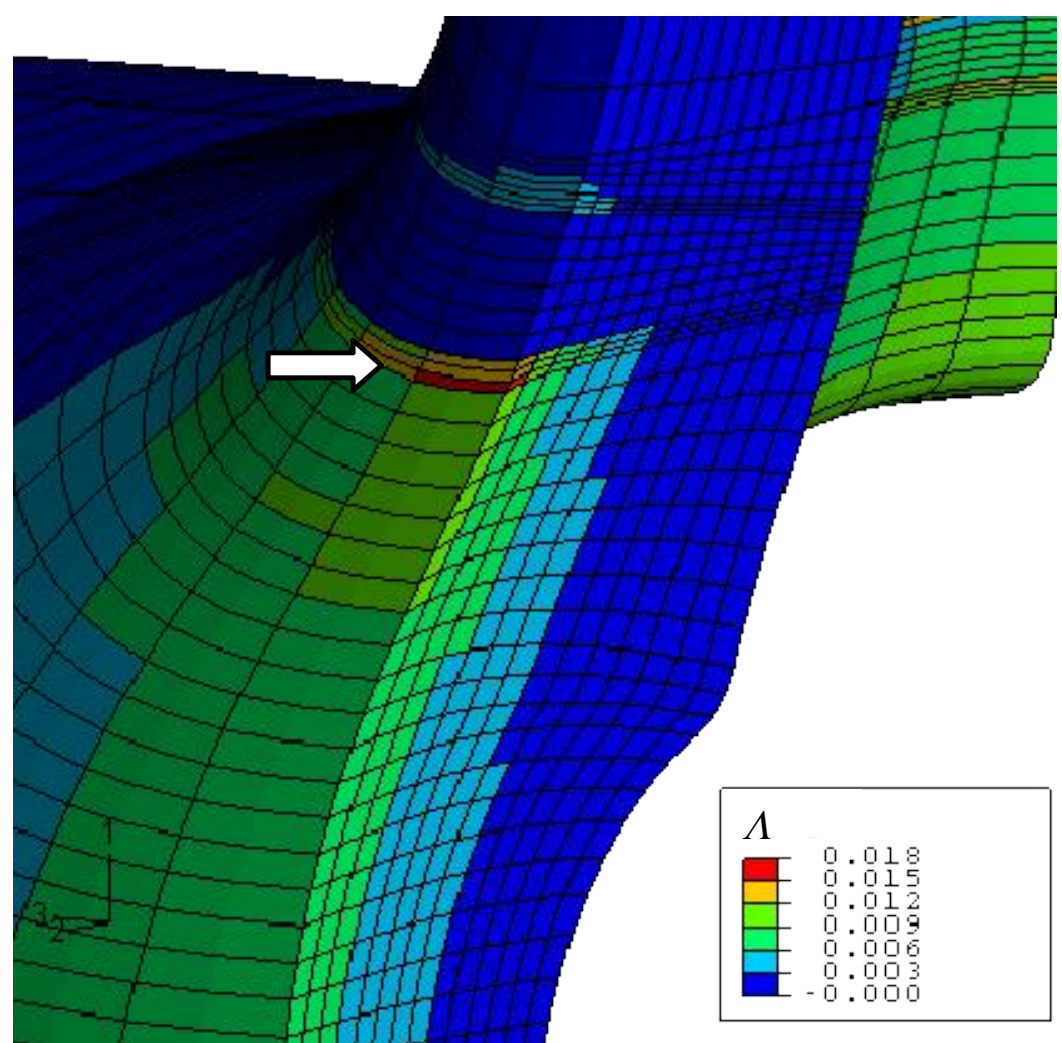

Fig. 5. Creep exhaustion (1-values) after $100000 \mathrm{~h} / 525^{\circ} \mathrm{C}$.

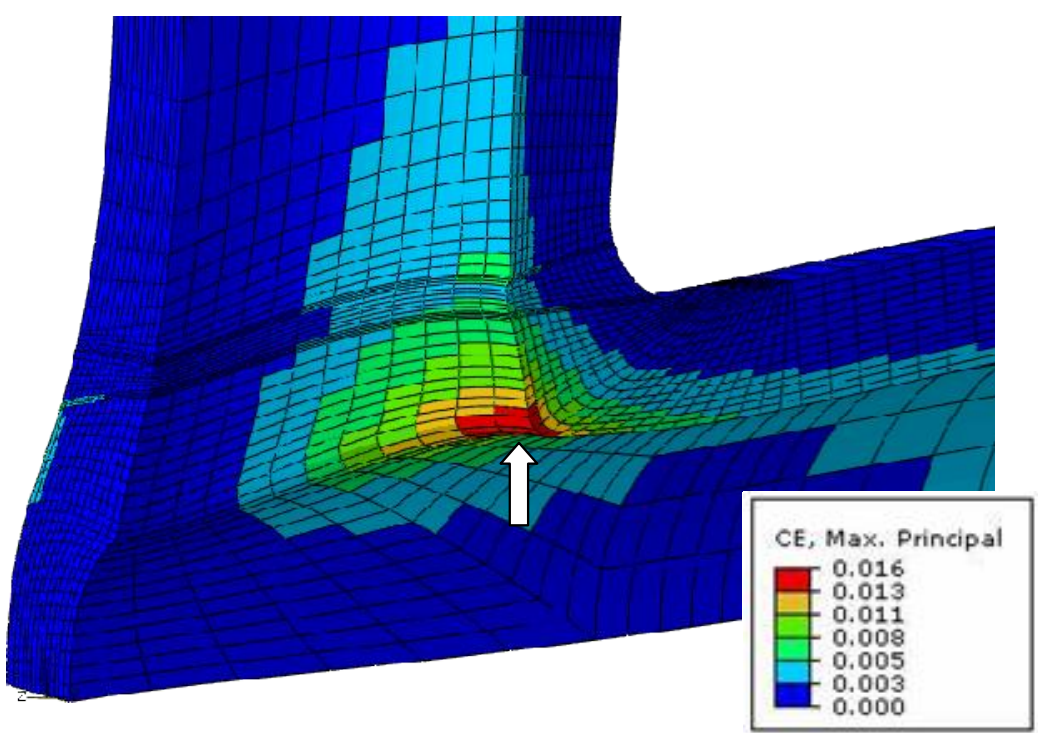

Fig. 6. Creep strain (maximum principal) after $100000 \mathrm{~h} / 525^{\circ} \mathrm{C}$, note location (inner surface BM) 


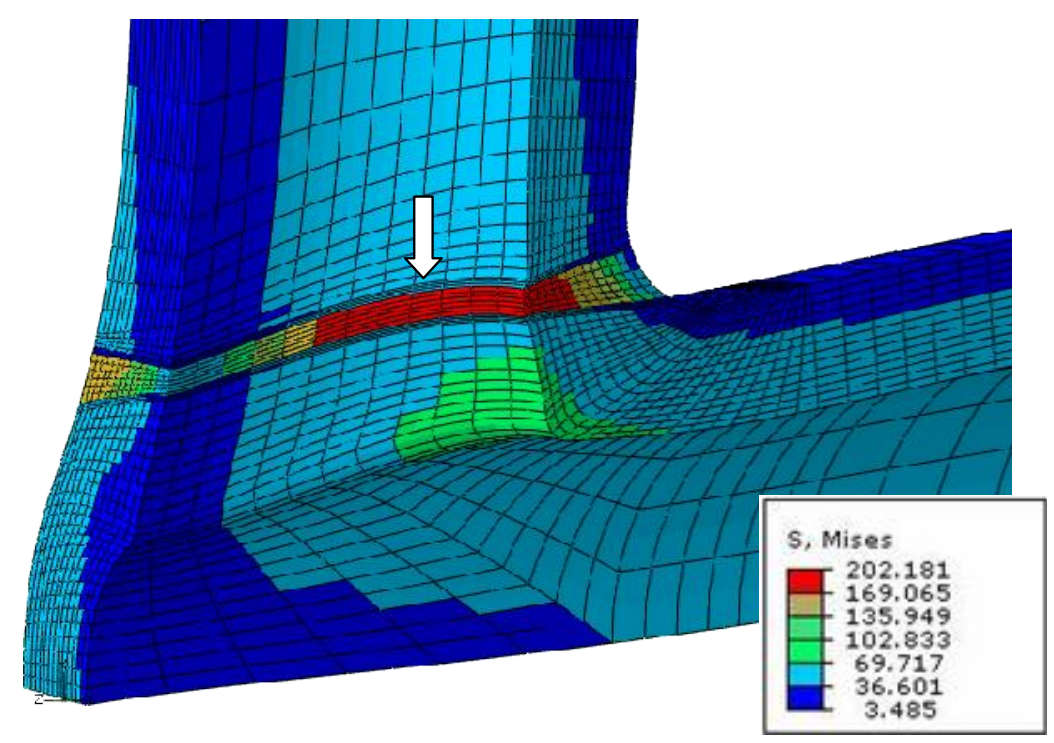

Fig. 7. Stress (von Mises) after $100000 \mathrm{~h} / 525^{\circ} \mathrm{C}$, note location (inner surface WM)

The maximum $\Lambda$-values acquired from the simulations with WM1 and WM2 seem low but when divided with values for uniaxial creep fracture strain as in Eq. 10, the consumed creep strain can be attained (see Table 3). At the point of observation $(100000 \mathrm{~h})$ the results are very reasonable for expected low ductility in uniaxial long term tests of cross welds.

Table 3. Consumed creep strain (\% of available) in the critical HAZ location of Fig. 5 after 100000 h of service (design pressure) as a function of uniaxial creep ductility.

\begin{tabular}{|c|c|}
\hline Uniaxial creep ductility & Consumed creep strain \\
\hline $10 \%$ & $15 \%$ \\
\hline $8 \%$ & $19 \%$ \\
\hline $6 \%$ & $25 \%$ \\
\hline $4 \%$ & $37 \%$ \\
\hline $2 \%$ & $75 \%$ \\
\hline $1.5 \%$ & $100 \%$ \\
\hline
\end{tabular}

As earlier stated the filtering technique as such does not require local creep ductility values since it is expressed as ratio dependent on stress and momentary multiaxial creep strain. The $600^{\circ} \mathrm{C}$ simulations with different $\mathrm{WM}$ show the difference in damaging mechanism. The weld with a over-matched weld metal (WM2) shows maximum $\Lambda$-values in the outer HAZ saddle point surface (see Fig. 8) and the weld with a very weak weld metal (WM3) fails prematurely due to extensive deformation in the WM (see Fig. 9). 


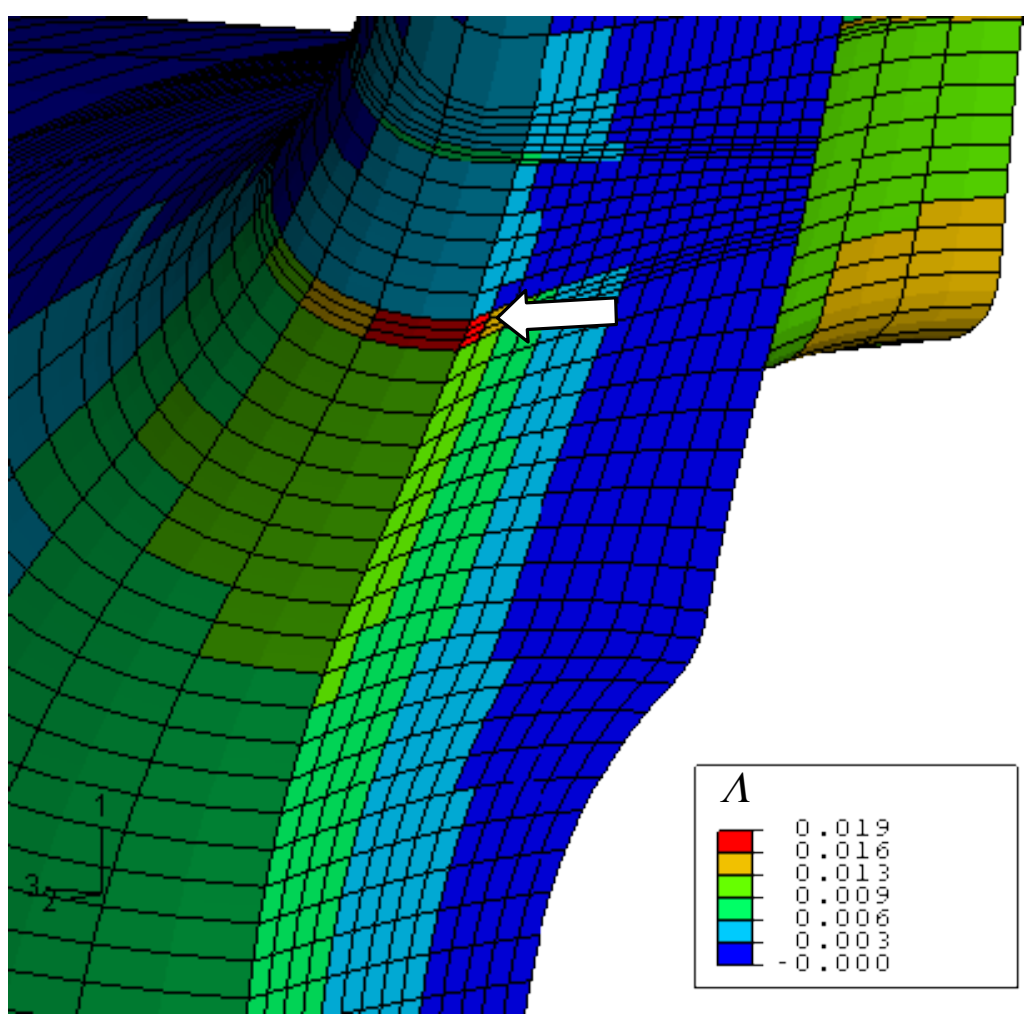

Fig. 8. Creep exhaustion after 1000 h at $600^{\circ} \mathrm{C}$ with over-matched weld metal (WM2). Compare with $525^{\circ} \mathrm{C}$ simulation in Fig. 5.

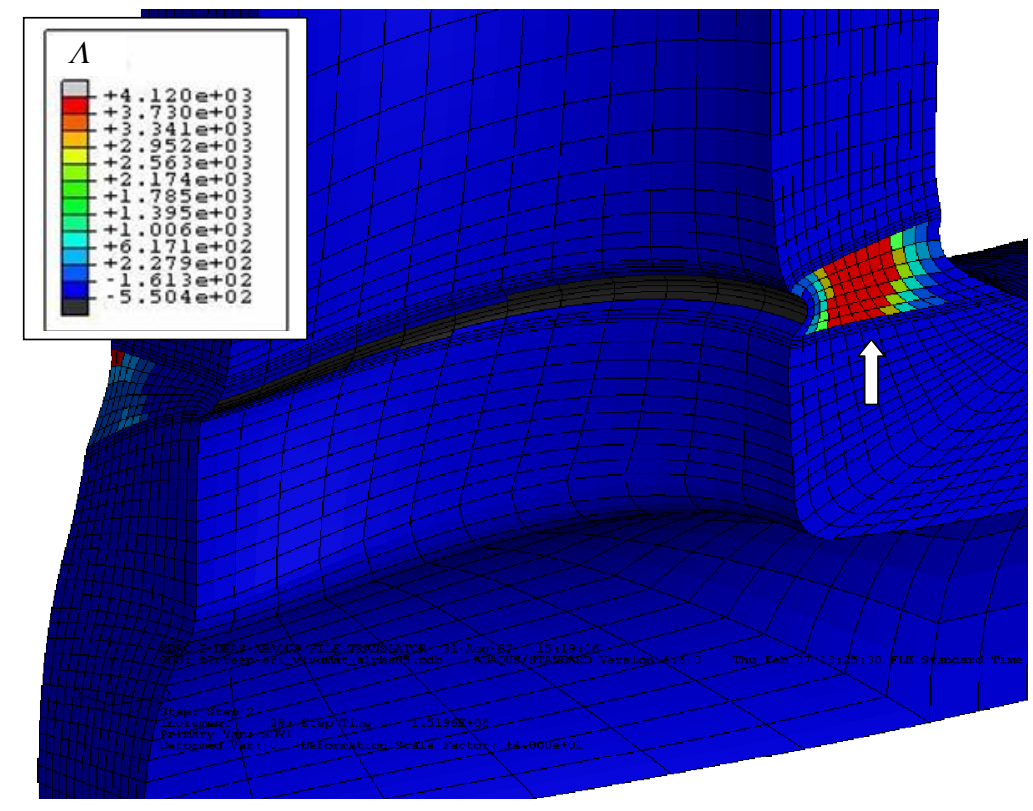

Fig. 9. Creep exhaustion after $422 \mathrm{~h}$ at $600^{\circ} \mathrm{C}$ with weak weld metal (WM3). Note the failing weld metal. 


\section{DISCUSSION AND CONCLUSIONS}

The LCSP creep strain model has been used for the steam mixer simulations, including primary to tertiary creep. The ABAQUS implementation of the model is working smoothly with satisfactory processing time. The numerical analysis, especially utilising the $\Lambda$-filtering technique seems to accurately pinpoint the critical damage locations of the steam mixer. The 3-zone weld simulation (BM, WM and HAZ) produce differing amounts of damage and a change of critical location depending on selected WM properties. Earlier inspection data exists for the case mixer and also for another mixer in the same power plant. This data will eventually be used for further calibration of the filtering technique. The current of the $\Lambda$-filter seem to work well for estimating the consumed creep strain but other forms more suitable for creep such as the creep ductility functions proposed by Cocks and Ashby referenced in [18], Andreas [13] or Spindler [14] should be tested for improved results. In conclusion it is quite evident that a powerful tool for high temperature component life assessments has been created and that advanced multiaxial creep modelling can now be performed with only a minimum amount of actual strain data. This feature will be especially handy for modelling structures with new materials with limited data and for pinpointing critical locations in components in service, thus improving inspection targeting. The new FEA tools will in the near future also be used for assessing large components made of P91 and X20 steels.

\section{ACKNOWLEDGEMENT}

The support of the Academy of Finland, decision nr. 117700 (Prof. Kim Wallin) is gratefully acknowledged. Fortum Power \& Heat is also gratefully acknowledged for all support related to the steam mixer case study.

\section{REFERENCES}

[1] Holmström S, Laukkanen A, Calonius K, Weldment matching for creep life of P22 and P91 girth welds. Conf. on Integrity of high temperature welds, 24-26 April 2007, London UK

[2] Hayhurst D. The use of computational creep continuum damage mechanics to optimise materials selection for high temperature weldments, Modelling Simul. Mater. Eng. 2, 1994, p.421-438.

[3] Perrin I, Hayhurst D, A method for the transformation of creep constitutive equations, Int. J. Pres. Ves. \& Piping 68, 1996, p299-309.

[4] Perrin I, Hayhurst D, Ainsworth A, Approximate creep rupture lifetimes for butt welded steel pressurised pipes. Eur. J. Mech. a/Solids 19, 2000, p.223-258. 
[5] Law M, Payten W, Weld performance under creep using finite element modelling, Int. J. Pres. Ves. \& Piping 72, 1997, p45-49

[6] Law M, Payten W, Snowden S, Creep Modeling of welded joints using the theta projection concept and finite element analysis, Journal of Pressure Vessel Technology, ASME transactions Vol. 122, 2000, p. 22-26.

[7] Hyde T.H, Sun W, Life prediction of repair welds in pressurised CrMoV pipe with incorporation of initial damage, Int. J. Pres. Ves. \& Piping 81, 2004, p1-12

[8] Wu R, Sandström R, Seitisleam F, Influence of extra coarse grains on the creep properties of 9 percent $\mathrm{CrMoV}$ (P91) steel weldment, Journal of engineering and technology, Transactions of ASME Vol. 126, p. 87-94.

[9] Becker A, Hyde T, Sun W, Andersson P, Benchmark for finite element analysis of creep continuum damage mechanics, Comp. Mat. Sci. 25, 2002, p 34-41.

[10]Law M, Payten W, Small R, Modelling the creep behaviour of reheat header longitudinal weld, Int. J. Pres. Ves. \& Piping 77, 2000, p.99-103.

[11]Hurst R.C, Rantala J.H. Influence of multiaxial stresses on creep and creep rupture of tubular components, ASM Handbook, Vol. 8, 2000 p. 405-411

[12] Webster G., Holdsworth S., Loveday M., Nikbin K., Perrin I., Purper H., Skelton R., Spindler M., Fatigue \& Fracture of Engineering Materials \& Structures, Volume 27, Number 4, April 2004 , pp. 319-342(24), Publisher: Blackwell Publishing

[13] Andreas, W. Evaluation of creep damage due to woid growth under traxial stress states in the design of steam turbine components. JSME. IntJ. Ser A 45, p. 72-77.

[14] Spindler M.W. The multiaxial creep ductility of austenitic stainless steels. Fatigue Fract Engng Mater Struct 27, 2004. p. 273-281.

[15] R5 (2001) Assessment procedure for the high temperature response of structures. British Energy, Glouchester UK.

[16] ASME (2000) Section III Div. 1. Sub-Section NH, ASME, New York, USA

[17]RCC-MR (1987) Design and construction rules for mechanical components of FBR nuclear islands, Paris France.

[18]Holmström S, Auerkari P, Robust prediction of full creep curves from minimal data and time to rupture, submitted to Energy Materials; Materials Science and Engineering for Energy Systems. doi:10.1179/174892406X173594, 2006, Vol 1. p249-255 
[19]Holmström, S., Auerkari, P., Holdsworth S. Predicting creep strain response from rupture data and robust creep curve model. International Conference on Life Management and Maintenance for Power Plants. Helsinki-Stockholm-Helsinki, 12-14 June 2007. Vol 1.

[20]Holmström, S., Laukkanen A., Calonius, K., Visualising creep exhaustion in a P22 girth weld. International Conference on Life Management and Maintenance for Power Plants. Helsinki-Stockholm-Helsinki, 12-14 June 2007. Vol 2. pp.208-221

[21] Webster G.A. High Temperature Component life assessment. Department of Mechanical Engineering, Imperial Collage of Science, ISBN 0-412-58520-0, Chapman \& Hall. 1994, p.37-38

[22]EN 10162, 2002. Seamless steel tubes for pressure purposes. Technical delivery conditions. Part 2: Non-alloy and alloy steel tubes with specified elevated temperature properties. CEN, Brussels.

[23] Holdsworth, S.R., 1996b. ECCC-WG1 Recommendations, Volume 5, Guidance for the Assessment of Creep Rupture, Creep Strain and Stress Relaxation Data, ECCC Document 5524:MC:38 Issue 3.

[24] Holdsworth S., Davies R., A recent advance in the assessment of creep rupture data Nuclear Engineering and Design, Volume 190, Issue 3, 2 June 1999, Pages 287-296

[25]DIN 17243. 1987. Weldable heat resisting steel forgings and rolled or forged steel bars; Technical delivery conditions. Deutche Institut für Normung E.V.

[26] Rantala, Juhani; Salonen, Jorma; Auerkari, Pertti; Holmström, Stefan; Lehtinen, O.; Pitkänen, M.; Nikkarila, R. Life extension of hot steam piping after $200000 \mathrm{~h}$ of service. Energy Materials: Materials Science \& Engineering for Energy Systems. Vol. 2 (2007) No: 2, 104-108(5)

[27]ABAQUS. 2007. ABAQUS Online Documentation: Version 6.7-1, Theory Manual [CD-ROM]. ABAQUS Inc.

[28]Holmström S., Laukkanen A., Calonius K., Finding critical damage locations by $\Lambda$-filtering in finiteelementmodelling of a girth weld, In press: Mater. Sci. Eng. A (2009), doi:10.1016/j.msea.2008.04.107

[29]Rice, J.R. and Tracey, D.M., On the Ductile Enlargement of Voids in Triaxial Stress Fields, Journal of the Mechanics and Physics of Solids, Vol. 17, Issue 3, 1969, Pages 201-217. 